\title{
DIFFERENTIAL ACCOUNTS OF CLOSENESS IN OLDER ADULT SIBLING RELATIONSHIPS
}

\author{
Annette L. Folwell \\ Western Oregon University \\ Leeva C. Chung, Jon F. Nussbaum \& Lisa Sparks Bethea \\ University of Oklahoma \\ Jo Anna Grant \\ University of Nebraska, Lincoln
}

\begin{abstract}
Research into the older adult sibling relationship has only recently recognized and attempted to account for differential feelings of closeness between siblings throughout their lives. Sixty-one participants, aged fifty-four and older with at least two siblings, were interviewed concerning the degree of closeness they felt towards their siblings. Participants in this investigation were able to differentiate levels of closeness felt toward their siblings and account for these differences. Family systems theory serves as a guide for these accounts.
\end{abstract}

KEY WORDS $\bullet$ closeness $\bullet$ older adults $\bullet$ siblings

Relationship scholars have recently focused their attention upon how specific familial relationships develop throughout life. Although marriage and parentchild relationships have received the majority of research attention from family researchers, the sibling relationship is one of the more intriguing, dynamic relationships to investigate. Approximately 90 percent of individuals who live beyond their 65th birthday have at least one living sibling (Cicirelli, 1982).

The sibling relationship is distinct from other family relationships. Nussbaum et al. (1989) propose that 'the sibling relationship is the best example of a lifespan developmental relationship' (p. 141). The structure of the sibling relationship is unique by virtue of the length, duration, common ethnic identity, and common early experiences within the family (Goetting, 1986). Consequently, the sibling relationship can be viewed as the most enduring

Address correspondence to Jon F. Nussbaum, Department of Communication, University of Oklahoma, 610 Elm Avenue, Norman, OK 73019, USA.

Journal of Social and Personal Relationships Copyright (C) 1997 SAGE Publications (London, Thousand Oaks, CA and New Delhi), Vol. 14(6): 843-849. [0265-4075 (199712) 14:6]. 
familial bond with the potential to last longer than both parent-child and spousal relationships (Cicirelli, 1980, 1989; Connidis, 1989).

One important area of study that has accumulated a body of research is emotional closeness. Emotional closeness is characterized as a sense of shared experiences, trust, concern, and enjoyment of the relationship (Lee et al., 1990). Feelings of closeness appear to increase through middle age and into older adulthood (Cicirelli, 1991). Furthermore, older adult sibling relationships express greater emotional closeness than younger sibling relationships (Goetting, 1986).

Three factors appear to affect the degree of closeness between adult siblings: (1) the sex composition of the dyad; (2) marital status; and (3) contact. First, sibling dyads with a female composition (i.e. at least one sister) are closer than male sibling dyads (Cicirelli, 1982, 1989). Second, marital status influences the dynamics of closeness in the adult sibling relationship; widowed or single siblings maintained closer sibling ties than married siblings (Connidis, 1989). Finally, closeness is associated with sibling contact. Lee et al. (1990) found that contact patterns are a major predictor of emotional closeness among siblings. Siblings who report feeling close to a sibling may have a history of shared contact (e.g. Lee et al., 1990; Ross \& Milgram, 1982).

Critical events can account for changes in the emotional closeness of siblings (Ross \& Milgram, 1982). Normative critical incidents are developmental in nature and can be expected to occur at certain stages of life, such as geographical moves, marriage of siblings, and loss of parents. Idiosyncratic critical incidents, such as violations of expectations, parental favoritism, and sibling competition, are unexpected or unpredictable events that occur in any stage of life.

One useful theory to help understand the development of closeness between siblings and the dynamic nature of this relationship is family systems theory which proposes that family structure is an open, sociocultural system in transformation (Minuchin, 1974). As the family develops, it passes through a number of states requiring reorganization. The family adapts to changing circumstances in a manner that maintains continuity while making restructuring possible. The family system carries out its functions through the operation of the spouse, parent-child, and sibling subsystems; the sibling subsystem is the primary context where children learn how to relate to peers through cooperation (warmth/closeness) and competition (relative status, power, conflict and rivalry).

In response to both internal and external pressures, the family system constantly adapts to stresses. Minuchin (1974) proposed four sources of family stress: (1) when one member has stressful contact with an extrafamilial force (e.g. the principle wage earner loses a job); (2) when the entire family has stressful contact with an extrafamilial source (e.g. when a family relocates); (3) when the family's own natural evolution requires renegotiation (e.g. the family changes, absorbs, or loses a member); and (4) when an individual member suffers trauma (e.g. a serious illness in the family). Any of these four stressors may overload the family's coping mechanisms causing the closeness and power dimensions of the family relationships to be renegotiated.

Family systems theory provides a useful framework for understanding the complexities of emotional closeness in sibling relationships. This theory suggests that sibling closeness will fluctuate as a result of family stressors. Other reviewed literature suggests that siblings may develop differential levels 
of closeness and that this closeness may fluctuate throughout life. Ross \& Migram's (1982) taxonomy of critical events and Minuchin's (1974) family systems specifically address the possibility that circumstances can lead to changes in sibling closeness. Past research about sibling closeness has not explored the dynamic aspects of sibling relationships later in life and little is known about fluctuations of closeness among siblings. The purpose of the present investigation is to discover whether older adult siblings perceive differing and/or fluctuating levels of emotional closeness toward their siblings and, if so, how they account for these differences. To this end, four research questions are addressed: RQ1: Do older individuals perceive emotional closeness differences in their sibling relationships? $\mathrm{RQ} 2$ : If emotional closeness differences are perceived, how do older individuals account for closeness differences in their sibling relationships? RQ3: Do older individuals perceive fluctuations of emotional closeness in sibling relationships across their lives? and RQ4: If fluctuations of emotional closeness are perceived, how do older individuals account for the fluctuations in their sibling relationships?

\section{Method}

Each member of an upper division undergraduate communication class identified 2 older adults to participate in this research project. The sample consisted of 61 adults $(M=31, F=30)$ over 54 years of age who had at least 2 siblings. The mean age of this sample was 70.5 years $(S D=7.7)$, with a range of 54-88 years. Participants had a mean total of 4.34 siblings with an average of 2.21 brothers and 2.13 sisters. Of the respondents, 69 percent had been married to current spouses for a mean of 30.7 years.

Class members collected the data. These student researchers were first trained in interviewing techniques and conducted mock interviews before administering a six-page interview questionnaire to the respondents. All interviews were conducted in a one-on-one setting.

The questionnaire consisted of three sections. The first section contained demographic questions addressing the age, sex, and marital status of participants, as well as information regarding the age and number of siblings in their family. In the second section, respondents were asked to think of the sibling with whom they felt closest and discuss the reasons for feeling close to that sibling. Participants were asked demographic information about this sibling (i.e. sex and age) and to rate their emotional closeness to this sibling on a 10 -point Likert-type scale $(0=$ not close at all; $10=$ very close $)$. Participants were asked how their relationship with this sibling had changed over time and to recall specific times during their life when they felt closest to this sibling. After answering each question, interviewers probed participants in greater depth. In the final section of the questionnaire, the participants were asked similar questions regarding their most emotionally distant sibling.

A coding scheme was developed combining Blumer's (1979) and Glaser \& Strauss' (1967) data analysis models to form concise categories from raw data. A two-fold process was employed to analyze the data. First, all distinct elements in the raw data were identified. Second, the elements were placed into common categories based upon emerging themes of sibling relationships. A codebook was constructed using these themes. In the codebook, each theme was identified, defined, and incorporated specific examples. The codebook was utilized to code the data for $\mathrm{RQ} 2$ and $\mathrm{RQ} 4$. 
Two authors coded a subsample consisting of 10 questionnaires (approximately $16 \%$ of the total sample) using the codebook generated from the emergent themes. To assess intercoder reliability, the presence or absence of an emergent theme for each question was tabulated for the percentage of agreement on a dichotomous variable. Results revealed an intercoder reliability of .92 using Holsti's (1969) formula. The remainder of the data were coded individually by the coders.

\section{Results}

The first research question asks whether older individuals perceive closeness differences in their sibling relationships. To answer this question, a twodependent sample $t$-test was employed to determine if individuals rated two siblings (closest and most distant) differently on a Likert-type scale. Results indicated that there is a significant difference between respondents' ratings of their closest vs their most distant sibling $(t=2.22$, d.f. $=59, p=.0258)$.

The second research question asks how older individuals account for closeness differences in their sibling relationships. The participants gave 3 primary reasons for feeling close to their closest sibling: (1) family events/ hardships; (2) commonalities; and (3) age-related issues. The participants accounted for the lack of closeness with their most distant sibling with 3 reasons: (1) the younger years; (2) tragedy/death/illness; and (3) never were close.

The third research question addresses whether older individuals perceive fluctuations of emotional closeness in sibling relationships. A chi-square analysis revealed that respondents perceive changes in closeness in their sibling relationships $\left(\chi^{2}=14.75\right.$, d.f. $\left.=1, \alpha=.05\right)$. Of the participants, 70 percent $(n=$ 43) perceived changes of emotional closeness in their sibling relationships, 23 percent $(n=14)$ did not report a change in closeness in their sibling relationships and 7 percent $(n=4)$ did not respond to the question.

Finally, the fourth research question asks how older adults account for the fluctuations in feelings of closeness towards their sibling. There were 3 emergent themes when participants considered their closest sibling: (1) commonalities; (2) proximity/contact; and (3) surrogate parent role. Conversely, the themes to emerge when participants considered their most distant sibling were: (1) personality differences; (2) less in common; and (3) less contact.

\section{Discussion}

This investigation examined differential accounts of closeness and fluctuations of closeness in the older adult sibling relationship. The finding from the first research question indicate that participants were able to make a clear distinction when rating close and distant siblings. In response to the second research question, older adults were able to account for these differences.

Events or stressors that transpire throughout one's life may significantly impact closeness levels at various times. These results support past research by Ross \& Milgram (1982) and Minuchin's (1974) family systems theory. In the present study, critical events/life stressors reflect examples of closeness among both close and distant siblings. Family stressors may bring siblings closer together or make them more distant. Respondents accounted for feelings of 
closeness by citing family events/hardships. The family events/hardships category was characterized as feeling close to a sibling when both siblings dealt with difficult circumstances together or when a drastic change in the family occurred. One participant stated that 'we got close when we were taking care of our sick father'. At the same time, tragedy/death/illness events account for levels of closeness among the most distant sibling relationships. Typical comments expressed that siblings were closer 'when I cared for my sick sibling' and '[at the] death of our parents'.

Closeness between siblings is not limited to specific events and life stressors as witnessed by two additional themes: commonalities and chronological age. Commonalities refers to interests, opinions, or beliefs that siblings share. Statements such as 'we always liked the same things', 'we've always shared everything', and 'we are philosophically compatible', illustrate an emotionally close bond between siblings based upon common interests and friendship. Older adults who never felt close to their siblings may be distant due to the lack of commonalities, pushing them farther apart. One participant observed, 'I [have] never been close with my brother and I never will'. Not all siblings grow up within an ideally close sibling relationship and certain distant sibling relationships remain distant.

Finally, age-related issues reflect patterns of closeness and distance due to chronological age. For example, one participant reflects that 'we were close because we were so close in age'. This finding is supported by McGhee (1985), who suggests that closeness among siblings may be felt because of similar age and mutual aging concerns. In addition, older adults who currently felt distant from their sibling reported higher levels of closeness in the past. The theme, younger years, was the most common theme reflected between distant siblings. A majority of the participants noted a sense of closeness 'when we were growing up together' and 'before we each got married'.

While a majority of older siblings reported fluctuations or changes of emotional closeness in their sibling relationships during their lifetime, a few reported no change. This finding is consistent with Ross \& Milgram's (1982) study, which found that most siblings felt emotional closeness to their siblings while a few stated that they never were close to their siblings or that their closeness levels had never changed.

When participants revealed the reasons they felt fluctuations of closeness toward their most distant sibling, three themes emerged: (1) less contact; (2) less in common; and (3) personality differences. These findings are consistent with previous reports that increased contact between siblings maintains feelings of closeness and lack of contact erodes these feelings (see Cicirelli, 1991; Ross \& Milgram, 1982). First, older adult participants who think of their closest sibling account for fluctuations of feelings in terms of commonalities. The sibling relationship may be closest during periods when similar interests and experiences are shared. Second, respondents repeatedly referred to feeling close due to proximity/contact because 'we stay in contact even though we are far apart', 'she calls frequently', and 'we live close together'. This is consistent with the finding that when siblings can and do maintain contact, feelings of closeness will be maintained (e.g. Cicirelli, 1991; Cicirelli \& Nussbaum, 1989). Finally, feelings of closeness during specific phases in the lifetime may be attributed to a relational function, such as a surrogate parent role. This theme consisted of comments such as 'she was a mother figure', 'he was always a father figure', and 'I always protected her'. 
Several limitations to this study should be recognized. First, the data from this study came from the perspective of one sibling. Although it would be difficult to interview both siblings, obtaining each sibling's descriptions and accounts of closeness may have aided the understanding of how life events cause closeness or distance or even a hostility between the siblings. Second, the use of a convenience sample has obvious limitations, such as non-, or overrepresentation of certain demographic groups. The third limitation pertains to the use of student interviewers to gather data. Although the student interviewers were trained thoroughly, there is still the potential for variation in the administration of the questionnaire. With different student interviewers, some degree of consistency may have been lost. This limitation may be a potential strength to this study; however, by employing different interviewers to obtain older adult participants, a more diverse sample may have been acquired.

Although this study found that older adults differ significantly in their closeness between siblings, it fails to quantify exactly how much these levels of closeness have fluctuated. Future research studies could utilize cross-sectional or longitudinal studies to examine how these levels of closeness change throughout life. Other lines of research could address the questions of sex differences in closeness fluctuation, the declining importance of age differences on sibling closeness, and what causes some siblings to develop a bond of emotional closeness while others do not. Finally, although this study shows that family stressors affect sibling closeness, the question remains: why do the same stressors seem to drive some siblings apart while bringing others closer together? The answers to these and other questions will help further understanding of one of the most common and enduring relationships of life.

\section{REFERENCES}

Blumer, M. (1979) 'Concepts in the Analysis of Qualitative Data', Sociological Review 27: 651-77.

Cicirelli, V.G. (1980) 'Sibling Influence in Adulthood: A Life Span Perspective', in L.W. Poon (ed.) Aging in the 80's, pp. 455-62. Washington, DC: American Psychological Association.

Cicirelli, V.G. (1982) 'Sibling Influence Throughout the Lifespan', in M.E. Lamb \& B. SuttonSmith (eds) Sibling Relationships: Their Nature and Significance Across the Lifespan, pp 267-84. Hillsdale, NJ: Erlbaum.

Cicirelli, V.G. (1989) 'Feelings of Attachment to Siblings and Well-being in Later Life', Psychology and Aging 4(2): 211-16.

Cicirelli, V.G. (1991) 'Sibling Relationships in Adulthood', Marriage and Family Review 16: 291-310.

Cicirelli, V.G. \& Nussbaum, J. (1989) 'Relationships with Siblings in Later Life', in J. Nussbaum (ed.) Lifespan Communication: Normative Process, pp. 283-97. Hillsdale, NJ: Erlbaum.

Connidis, I.A. (1989) 'Contact Between Siblings in Later Life', Canadian Journal of Sociology 14: 429-42.

Glaser, B.G. \& Strauss, A.L. (1967) The Discovery of Grounded Theory: Strategies for Qualitative Research. Chicago, IL: Aldine.

Goetting, A. (1986) 'The Development Tasks of Siblingship Over the Life Cycle', Journal of Marriage and the Family 48: 703-14.

Holsti, O.R. (1969) Content Analysis for the Social Sciences and Humanities. Reading, MA: Addison-Wesley. 
Lee, T.R., Mancini, J.A. \& Maxwell, J.W. (1990) 'Sibling Relationships in Adulthood: Contact Patterns and Motivation', Journal of Marriage and the Family 52: 431-40.

McGhee, J.L. (1985) 'The Effects of Sibling on the Life Satisfaction of the Rural Elderly', Journal of Marriage and the Family 47: 85-91.

Minuchin, S. (1974) Families and Family Therapy. Cambridge, MA: Harvard University Press.

Nussbaum, J., Thompson, T. \& Robinson, J. (1989) Communication and Aging. New York: Harper \& Row.

Ross, H.G. \& Milgram, J.I. (1982) 'Important Variables in Adult Sibling Relationships: A Qualitative Study', in M.E. Lamb \& B. Sutton-Smith (eds) Sibling Relationships: Their Nature and Significance Across the Lifespan, pp. 225-49. Hillsdale, NJ: Erlbaum. 